\title{
Impact of intra-aortic balloon pump on long-term mortality of unselected patients with ST-segment elevation myocardial infarction complicated by cardiogenic shock
}

\author{
Artur Dziewierz' ${ }^{1}$ Zbigniew Siudak ${ }^{2}$, Tomasz Rakowski ${ }^{1}$, Paweł Kleczyński ${ }^{1}$, Wojciech Zasada ${ }^{1}$, Dariusz Dudek ${ }^{2}$ \\ ${ }^{1} 2^{\text {nd }}$ Department of Cardiology, Jagiellonian University Medical College, Krakow, Poland \\ ${ }^{2}$ Department of Interventional Cardiology, Jagiellonian University Medical College, Krakow, Poland
}

Postep Kardiol Inter 2014; 10, 3 (37): 175-180 DOI: $10.5114 /$ pwki.2014.45144

\begin{abstract}
A b s tract
Introduction: A large, randomised trial (IABP-SHOCK II) confirmed no benefit of intra-aortic balloon pump (IABP) on clinical outcomes of patients with ST-segment elevation myocardial infarction (STEMI) complicated by cardiogenic shock. However, the 'sickest' patients are often excluded from randomised clinical trials, so it is difficult to generalise expected outcomes from randomized clinical trials to the real life setting.

Aim: We sought to evaluate the impact of IABP on 1-year mortality of unselected patients with STEMI presenting in cardiogenic shock.

Material and methods: Data were gathered for 1,650 consecutive patients with STEMI transferred for primary angioplasty from hospital networks in 7 countries in Europe from November 2005 to January 2007 (the EUROTRANSFER registry population). Of them, 51 patients with cardiogenic shock on admission were identified and stratified based on the use of IABP. Outcome results were adjusted for age and sex, to control possible selection bias.

Results: At the discretion of the operators, IABP was applied in 30 patients (58.8\%, IABP group). The remaining 21 patients were treated without IABP (no-IABP group). The use of IABP was more frequent among males, younger patients, and patients with STEMI of the anterior wall. There was no difference in 30-day mortality in patients with and without IABP (no-IABP vs. IABP: $38.1 \%$ vs. $33.3 \%$; adjusted OR 1.79 (95\% Cl 0.43-7.52); $p=0.43$ ). Similarly, IABP had no impact on 1-year mortality (42.9\% vs. 33.3\%; adjusted OR 1.27 (95\% Cl 0.32-5.09); $p=0.74)$. One-year mortality was comparable among patients who survived hospitalisation (14.3\% vs. 13\%; $p=0.64)$.

Conclusions: We observed no benefit of IABP on short - and long-term mortality of unselected patients with STEMI complicated by cardiogenic shock.
\end{abstract}

Key words: intra-aortic balloon pump, counterpulsation, cardiogenic shock, myocardial infarction, angioplasty, registries.

\section{Introduction}

Cardiogenic shock is the leading cause of death among patients hospitalised with ST-segment elevation myocardial infarction (STEMI) [1-7]. Early revascularisation, with both percutaneous coronary intervention (PCI) and coronary artery bypass grafting (CABG) leads to a survival benefit in these patients $[8,9]$. According to current guidelines, additional intra-aortic balloon pump (IABP) support may be considered in patients with STEMI and cardiogenic shock [10,11].

Intra-aortic balloon pump improves myocardial and peripheral perfusion, and reduces afterload, as well as myocardial oxygen consumption [6, 12-14]. These effects are believed to improve myocardial recovery during isch- aemia and reperfusion. On the other hand, the benefit of IABP in patients with STEMI and cardiogenic shock undergoing primary $\mathrm{PCl}$ were not proven by a meta-analysis of cohort studies [15]. In addition, the impact of IABP on long-term survival of patients with STEMI and cardiogenic shock remains unclear because the majority of previous studies have focused on short-term outcomes [15-19]. Recently, a large, randomised IABP-SHOCK II trial confirmed no benefit of IABP on short - and long-term outcomes of patients with STEMI complicated by cardiogenic shock [20, 21]. However, the 'sickest' patients are often excluded from randomised clinical trials, so it is difficult to generalise expected outcomes from randomized clinical trials to the real life setting.

\section{Corresponding author:}

Dariusz Dudek MD, PhD, Department of Interventional Cardiology, Jagiellonian University Medical College, 17 Kopernika St, $31-501$ Krakow, Poland, phone: +48 1242471 81, fax: +48 1242471 84, e-mail: mcdudek@cyfronet.pl

Received: 15.05 .2014 , accepted: 14.07.2014. 


\section{Aim}

We sought to evaluate the impact of IABP on 1-year mortality in an unselected cohort of patients with STEMI complicated by cardiogenic shock, based on data from the EUROTRANSFER (European Registry on Patients with ST-Elevation MI Transferred for Mechanical Reperfusion with a Special Focus on Upstream Use of Abciximab) Registry [22-24].

\section{Material and methods}

The EUROTRANSFER Registry (ClinicalTrials.gov number NCT00378391) design and main results have been published elsewhere [22-24]. In this registry, data on 1,650 patients with STEMI in 15 primary $\mathrm{PCl}$ networks from 7 European countries between November 2005 and January 2007 were collected. For the present analysis, the data of 51 (3.1\%) patients with STEMI and cardiogenic shock on admission (systolic blood pressure $<90 \mathrm{~mm} \mathrm{Hg}$, heart rate $>100 \mathrm{bpm}$, and clinical signs of organ hypoperfusion) were assessed. Patients were stratified by use of IABP during index hospital stay: no-IABP vs. IABP. The treatment strategies, including the use of IABP and the timing of insertion, were at the discretion of operators. The study protocol and execution complied with the Declaration of Helsinki and was approved by the Institutional Review Board.

The primary endpoint was 1-year all-cause mortality. Secondary endpoints were: 30-day all-cause mortality, nonfatal reinfarction, urgent revascularisation $(\mathrm{PCl}$ or CABG), major bleeding requiring transfusion, and puncture site haematoma [22-24]. Thrombolysis In Myocardial infarction (TIMI) flow in the infarct-related artery before and after $\mathrm{PCl}$, ST-segment resolution after $\mathrm{PCl}$, and the rate of angiographic complications of $\mathrm{PCl}$ (no-reflow, distal embolisation) were assessed at the investigators' discretion.

\section{Statistical analysis}

Continuous variables were presented as medians (interquartile ranges). Categorical variables were expressed as numbers (percentages). Differences between groups (no-IABP vs. IABP) were tested using the $\chi^{2}$ test and Fisher's exact test for dichotomous variables and the Mann-Whitney U-test for continuous variables. The effect of IABP vs. no-IABP on clinical outcomes was presented as odds ratios (OR) and 95\% confidence intervals (CI). To adjust for possible selection bias, differences in clinical outcomes were adjusted for age and sex using logistic regression. Results were presented as adjusted OR with $95 \% \mathrm{Cl}$. The survival curves were estimated by the Kaplan-Meier method and compared using log-rank test. All tests were 2 -tailed, and a $p$ value of $<0.05$ was considered statistically significant. All statistical analysis was performed using SPSS software, version 15.0 (SPSS Inc., Chicago, Illinois).

\section{Results}

In total, 1,650 patients with STEMI from 15 primary $\mathrm{PCl}$ centres between November 2005 and January 2007 were included in the EUROTRANSFER Registry. Of these, $51(3.1 \%)$ patients were in cardiogenic shock on admission. At the discretion of the operators, IABP was used in 30 patients (58.8\%, IABP group). The remaining 21 patients were treated without IABP (41.2\%, no-IABP group). As shown in Tables I and II, the use of IABP was more frequent among males, younger patients, and patients with the left anterior descending artery as the infarct-related artery.

\section{Impact of intra-aortic balloon pump on clinical outcomes}

Immediate $\mathrm{PCl}$ was performed in $30(100 \%)$ patients from the IABP group, and in 18 (85.7\%) patients from the no-IABP group $(p=0.06)$. Two patients from the no-IABP group were transferred for urgent CABG. The rate of stent implantation and thrombus aspiration was comparable between the two groups (Table II). Despite no difference in the rate of TIMI grade 3 flow after $\mathrm{PCl}$, the rate of ST-segment resolution > 50\% 60 min after $\mathrm{PCl}$ was numerically higher in patients from the no-IABP group (noIABP vs. IABP: $47.6 \%$ vs. $26.7 \%$; $p=0.15$ ).

The overall 30 -day and 1-year mortality for patients in cardiogenic shock was $35.3 \%$ and $37.3 \%$, respectively. Even after adjustment for age and sex, there was no difference in short - and long-term mortality between patients treated with and without IABP (Table III, Figure 1). Similarly, no difference in 1-year mortality was observed when the infarct-related artery (left anterior descending artery (LAD) vs. no-LAD) and diabetes mellitus were added to the adjustment model - adjusted OR $(95 \% \mathrm{Cl})-1.48$ (0.30-7.33). There was also no difference in 1-year mortality between groups of patients who survived hospitalisation (no-IABP vs. IABP: $14.3 \%$ vs. $13.0 \% ; p=0.64$ ). The rate of bleedings was comparable between groups (Table III).

\section{Discussion}

The main finding of the present study is that among patients with STEMI complicated by cardiogenic shock, treatment with IABP had no impact on short - and longterm survival. On the other hand, despite the higher risk attributed to patients from the IABP group, the long-term outcomes were comparable to those observed in lower-risk patients treated without IABP. This may suggest a beneficial effect of IABP in a selected group of patients.

The observed rate of cardiogenic shock on admission was comparable to that previously reported for patients with STEMI $[3-5,7]$. Also, short - and long-term mortality rates were similar to those reported for patients undergoing early revascularisation in the setting of STEMI complicated by cardiogenic shock [4, 5, 8, 9, 17, 18, 25]. 
Table I. Baseline clinical characteristics of patients with and without intra-aortic balloon pump

\begin{tabular}{lccc} 
Variable & \multicolumn{2}{c}{ Intra-aortic balloon pump } & \multirow{2}{*}{ Value of $p$} \\
\cline { 2 - 3 } & $\begin{array}{c}\text { No } \\
\left(\begin{array}{l}n=21) \\
(n=30)\end{array}\right.\end{array}$ & $\begin{array}{c}\text { Yes } \\
(\%) / \text { median (range) }\end{array}$ \\
\hline Age [years] & $72(62-81)$ & $64.5(52-74)$ & 0.018 \\
\hline Age $\geq 65$ years & $14(66.7)$ & $15(50.0)$ & 0.24 \\
\hline Men & $8(38.1)$ & $25(83.8)$ & 0.001 \\
\hline Body mass index [kg/m²] & $26.9(23.2-28.5)$ & $27.4(24.7-29.3)$ & 0.24 \\
\hline Diabetes mellitus & $1(4.8)$ & $8(26.7)$ & 0.06 \\
\hline Previous myocardial infarction & $4(19.0)$ & $8(26.7)$ & 0.74 \\
\hline Previous heart failure symptoms & $1(4.8)$ & $2(6.7)$ & 0.99 \\
\hline Previous percutaneous coronary intervention & $1(4.8)$ & $2(6.7)$ & 0.99 \\
\hline Previous coronary artery bypass grafting & $0(0.0)$ & $0(0.0)$ & - \\
\hline Current smoker & $5(23.8)$ & $8(26.7)$ & 0.82 \\
\hline Peripheral arterial disease & $1(4.8)$ & $0(0.0)$ & 0.41 \\
\hline Previous stroke & $2(9.5)$ & $0(0.0)$ & 0.17 \\
\hline Chronic kidney disease & $1(4.8)$ & $0(0.0)$ & 0.41 \\
\hline Time from symptoms onset to diagnosis [min] & $92(53-133)$ & $80(45-293)$ & 0.72 \\
\hline Aspirin before cathlab & $15(71.4)$ & $26(86.7)$ & 0.28 \\
\hline Clopidogrel before cathlab & $2(9.5)$ & $7(23.3)$ & 0.28 \\
\hline Unfractionated heparin before cathlab & $13(61.9)$ & $16(53.3)$ & 0.54 \\
\hline Abciximab before cathlab & $5(23.8)$ & $14(46.7)$ & 0.14
\end{tabular}

Values are presented as numbers (percentages) or medians (inter-quartile range)

Table II. Invasive treatment details of patients with and without intra-aortic balloon pump

\begin{tabular}{|c|c|c|c|}
\hline \multirow[t]{2}{*}{ Variable } & \multicolumn{2}{|c|}{ Intra-aortic balloon pump } & \multirow[t]{2}{*}{ Value of $p$} \\
\hline & $\begin{array}{c}\text { No } \\
(n=21) \\
n(\%) / \text { median (range) }\end{array}$ & $\begin{array}{c}\text { Yes } \\
(n=30) \\
n(\%) / \text { median (range) }\end{array}$ & \\
\hline Femoral access & $20(95.2)$ & $27(90.0)$ & 0.63 \\
\hline LAD as infarct-related artery & $8(38.1)$ & $20(66.7)$ & 0.044 \\
\hline Multi-vessel disease & $16(76.2)$ & $20(69.0)$ & 0.57 \\
\hline TIMI grade 2 to 3 flow before $\mathrm{PCI}$ & $3(14.3)$ & $3(10.0)$ & 0.68 \\
\hline Time from symptoms onset to PCI [min] & $226(139-352)$ & $220(136-460)$ & 0.87 \\
\hline Immediate PCl & $18(85.7)$ & $30(100)$ & 0.06 \\
\hline \multicolumn{4}{|l|}{ Number of stents implanted: } \\
\hline 1 & $11(68.8)$ & $17(65.4)$ & 0.69 \\
\hline 2 & $3(18.8)$ & $7(26.9)$ & \\
\hline 3 & $2(12.5)$ & $1(3.8)$ & \\
\hline$\geq 4$ & $0(0.0)$ & $1(3.8)$ & \\
\hline Thrombus aspiration & $1(5.6)$ & $5(16.7)$ & 0.39 \\
\hline Drug-eluting stent & $7(38.9)$ & $8(26.7)$ & 0.52 \\
\hline Non-infarct-related artery PCI & $2(11.1)$ & $4(13.3)$ & 0.99 \\
\hline TIMI grade 3 flow after $\mathrm{PCl}$ & $16(88.9)$ & $24(80.0)$ & 0.81 \\
\hline \multicolumn{4}{|l|}{ Angiographic complications of $\mathrm{PCl}$ : } \\
\hline No-reflow & $0(0.0)$ & $2(6.7)$ & 0.52 \\
\hline Distal embolisation & $0(0.0)$ & $2(6.7)$ & 0.52 \\
\hline
\end{tabular}

Values are presented as numbers (percentages) or medians (inter-quartile range). LAD - the left anterior descending artery, $P C I$ - percutaneous coronary intervention, TIMI - Thrombolysis In Myocardial Infarction 
Table III. Clinical outcomes of patients with and without intra-aortic balloon pump

\begin{tabular}{|c|c|c|c|c|c|c|}
\hline \multirow[t]{2}{*}{ Variable } & \multicolumn{2}{|c|}{ Intra-aortic balloon pump } & \multirow[t]{2}{*}{ OR $(95 \% \mathrm{Cl})$} & \multirow{2}{*}{$\begin{array}{l}\text { Value } \\
\text { of } p\end{array}$} & \multirow{2}{*}{$\begin{array}{l}\text { Adjusted OR } \\
\quad(95 \% \mathrm{Cl})\end{array}$} & \multirow{2}{*}{$\begin{array}{l}\text { Value } \\
\text { of } p\end{array}$} \\
\hline & $\begin{array}{c}\text { No } \\
(n=21) \\
n(\%)\end{array}$ & $\begin{array}{c}\text { Yes } \\
(n=30) \\
n(\%)\end{array}$ & & & & \\
\hline \multicolumn{7}{|l|}{ 30-day: } \\
\hline Death & $8(38.1)$ & $10(33.3)$ & $0.81(0.25-2.60)$ & 0.73 & $1.79(0.43-7.52)$ & 0.43 \\
\hline Death + nonfatal reinfarction & $9(42.9)$ & $11(36.7)$ & $0.77(0.25-2.41)$ & 0.66 & $1.45(0.36-5.78)$ & 0.60 \\
\hline $\begin{array}{l}\text { Death + nonfatal reinfarction + } \\
\text { urgent revascularisation }\end{array}$ & $9(42.9)$ & $14(46.7)$ & $1.17(0.38-3.59)$ & 0.79 & $2.53(0.61-10.45)$ & 0.20 \\
\hline $\begin{array}{l}\text { Major bleeding requiring } \\
\text { transfusion }\end{array}$ & $1(4.8)$ & $1(3.2)$ & $0.69(0.04-11.68)$ & 0.99 & $1.36(0.05-38.88)$ & 0.86 \\
\hline Puncture site haematoma & $2(9.5)$ & $2(6.7)$ & $0.68(0.09-5.24)$ & 0.99 & $1.08(0.11-11.13)$ & 0.95 \\
\hline \multicolumn{7}{|l|}{ 1-year: } \\
\hline Death & $9(42.9)$ & $10(33.3)$ & $0.67(0.21-2.11)$ & 0.49 & $1.27(0.32-5.09)$ & 0.74 \\
\hline
\end{tabular}

Values are presented as numbers (percentages) and as odds ratios (OR) with $95 \%$ confidence intervals (CI), unadjusted and adjusted for age and sex

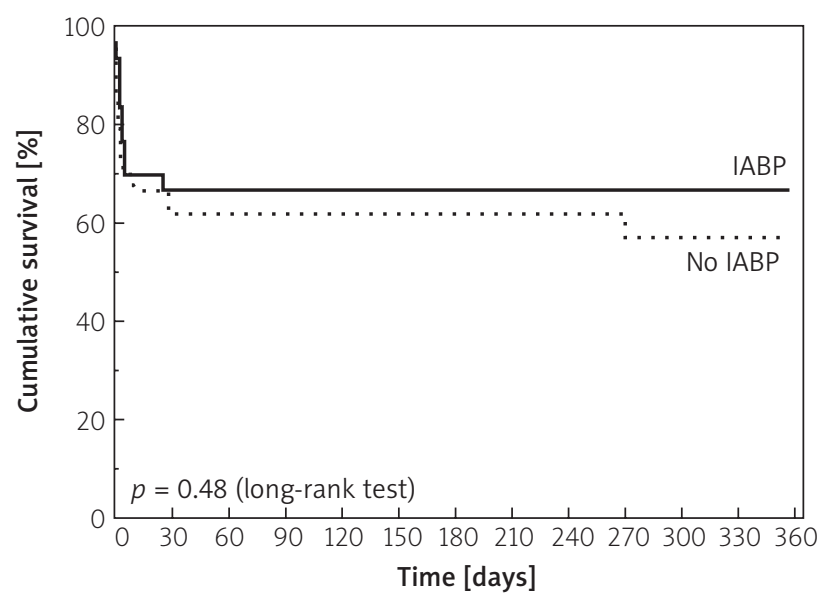

Figure 1. Kaplan-Meier survival curves for patients treated with (solid line) and without (dotted line) intra-aortic balloon pump

In our study, IABP was used in up to $60 \%$ of patients with STEMI and cardiogenic shock on admission. Conversely, it was used in $25 \%$ of patients with cardiogenic shock included between May 2005 and April 2008 in the Euro Heart Survey on $\mathrm{PCl}$ [18]. A more recent report from the ALKK-PCI registry confirms significant differences in the use of IABP between various German hospitals, ranging from 0 to $70 \%$, with an overall rate of $25.5 \%$ [17]. The recent decrease in the use of IABP in Europe [17, 18, $26]$ is probably related to the results of a meta-analysis of cohort studies from Sjauw et al. published on 2009 [15]. In this meta-analysis no mortality benefit of IABP in patients with STEMI complicated by cardiogenic shock treated with primary $\mathrm{PCl}$ was confirmed. Importantly, the use of IABP was associated with an increase in major bleeding complications and stroke [15]. In the largest study to date on IABP support in patients with STEMI complicated with cardiogenic shock (the IABP-SHOCK II trial), no reduction of 30-day and 1-year mortality was observed in patients treated with IABP, as compared to patients without IABP [20, 21]. Also, there was no difference in other clinical endpoints, including stroke. In the updated meta-analysis from Romeo et al. (13 observational studies, 4 randomised clinical trials) a significant increase of in-hospital mortality was observed in patients with cardiogenic shock undergoing primary $\mathrm{PCl}$ supported by IABP [19]. Interestingly, the benefit of IABP was limited to patients with STEMI and cardiogenic shock treated with thrombolytic therapy [19].

Using the data from the EUROTRANSFER registry, we observed no impact of IABP on short-term mortality of patients with STEMI and cardiogenic shock on admission. Our study may also suggest that IABP support in patients with STEMI and cardiogenic shock on admission did not improve long-term clinical outcomes compared to no IABP. Importantly, observed 1-year mortality rates for patients who survived hospitalisation were low, and comparable between groups. This finding is in line with the results of the study from Singh et al. [27] In this study, the long-term mortality of patients with STEMI and cardiogenic shock, and who survived hospitalisation, was low and similar to that reported for patients with STEMI without cardiogenic shock [28, 29].

Our study has a number of potential limitations. This is a non-randomised study with the potential of selection bias. The two groups were not balanced for important factors affecting long-term outcomes in patients with STEMI (gender, age, infarct location, and diabetes mellitus). Due to the very small sample size, the study was underpowered for the assessment of clinical endpoints. We were unable to calculate propensity scores or to control patient-, operator-, and centre-related factors influencing the association between IABP use and patient outcomes. The analysed 1-year outcomes were limited to 
mortality only, and important data on heart failure symptoms or neurological outcomes were not available. Also, we were unable to assess the impact of IABP timing on clinical outcomes because no data on the timing of IABP insertion (before, during, or after angiography/PCI) were available. The study by Abdel-Wahab et al. suggests that patients with cardiogenic shock (either on admission or during hospitalisation) undergoing primary $\mathrm{PCl}$ assisted by IABP have a more favourable in-hospital outcome and lower in-hospital mortality than patients who receive IABP after $\mathrm{PCI}$ [30]. Conversely, no association between the time of IABP insertion (before $\mathrm{PCI}$ vs. after $\mathrm{PCI}$ ) and 30-day mortality was reported for patients with cardiogenic shock on admission [31]. In addition, no data on the use of antithrombotic and antiplatelet drugs, as well as inotropes/vasopressors during index hospital stay, were collected in the EUROTRANSFER registry, and no data on important admission laboratory predictors of mortality in cardiogenic shock, such as glucose, lactate, and creatinine clearance, were available.

\section{Conclusions}

We observed no benefit of IABP on short - and longterm mortality of unselected patients with STEMI complicated by cardiogenic shock.

\section{Acknowledgments}

EUROTRANSFER Registry was an academic research project that was supported by a research grant from Eli Lilly and Company, Critical Care Europe, Geneva, Switzerland.

\section{References}

1. Granger CB, Goldberg RJ, Dabbous O, et al. Predictors of hospital mortality in the global registry of acute coronary events. Arch Intern Med 2003; 163: 2345-53.

2. Holmes DR Jr, Berger PB, Hochman JS, et al. Cardiogenic shock in patients with acute ischemic syndromes with and without ST-segment elevation. Circulation 1999; 100: 2067-73.

3. Dziewierz A, Siudak Z, Rakowski T, et al. Predictors and in-hospital outcomes of cardiogenic shock on admission in patients with acute coronary syndromes admitted to hospitals without on-site invasive facilities. Acute Card Care 2010; 12: 3-9.

4. Babaev A, Frederick PD, Pasta DJ, et al. Trends in management and outcomes of patients with acute myocardial infarction complicated by cardiogenic shock. JAMA 2005; 294: 448-54.

5. Jeger RV, Radovanovic D, Hunziker PR, et al. Ten-year trends in the incidence and treatment of cardiogenic shock. Ann Intern Med 2008; 149: 618-26.

6. Fuernau $G$, Thiele $H$. The spectrum of haemodynamic support in cardiogenic shock: how to choose and use. Kardiol Pol 2012; 71: 887-92.

7. Gasior M, Pres D, Gierlotka M, et al. The influence of diabetes on in-hospital and long-term mortality in patients with myocardial infarction complicated by cardiogenic shock: results from the PL-ACS registry. Kardiol Pol 2012; 70: 1215-24.
8. Hochman JS, Sleeper LA, Webb JG, et al. Early revascularization in acute myocardial infarction complicated by cardiogenic shock. SHOCK Investigators. Should we emergently revascularize occluded coronaries for cardiogenic shock. N Engl J Med 1999; 341: 625-34.

9. Hochman JS, Sleeper LA, Webb JG, et al. Early revascularization and long-term survival in cardiogenic shock complicating acute myocardial infarction. JAMA 2006; 295: 2511-5.

10. Steg PG, James SK, Atar D, et al. ESC Guidelines for the management of acute myocardial infarction in patients presenting with ST-segment elevation. Eur Heart J 2012; 33: 2569-619.

11. O'Gara PT, Kushner FG, Ascheim DD, et al. 2013 ACCF/AHA guideline for the management of ST-elevation myocardial infarction: executive summary: a report of the American College of Cardiology Foundation/American Heart Association Task Force on Practice Guidelines. Circulation 2013; 127: 529-55.

12. de Waha S, Desch S, Eitel I, et al. What is the evidence for IABP in STEMI with and without cardiogenic shock? Ther Adv Cardiovasc Dis 2012; 6: 123-32.

13. Ishihara $\mathrm{M}$, Sato $\mathrm{H}$, Tateishi $\mathrm{H}$, et al. Effects of intraaortic balloon pumping on coronary hemodynamics after coronary angioplasty in patients with acute myocardial infarction. Am Heart J 1992; 124: 1133-8.

14. Kern MJ, Aguirre FV, Tatineni S, et al. Enhanced coronary blood flow velocity during intraaortic balloon counterpulsation in critically ill patients. J Am Coll Cardiol 1993; 21: 359-68.

15. Sjauw KD, Engstrom AE, Vis MM, et al. A systematic review and meta-analysis of intra-aortic balloon pump therapy in ST-elevation myocardial infarction: should we change the guidelines? Eur Heart J 2009; 30: 459-68.

16. Prondzinsky R, Unverzagt $S$, Russ $M$, et al. Hemodynamic effects of intra-aortic balloon counterpulsation in patients with acute myocardial infarction complicated by cardiogenic shock: the prospective, randomized IABP shock trial. Shock 2012; 37: 378-84.

17. Zeymer U, Hochadel M, Hauptmann KE, et al. Intra-aortic balloon pump in patients with acute myocardial infarction complicated by cardiogenic shock: results of the ALKK-PCI registry. Clin Res Cardiol 2013; 102: 223-7.

18. Zeymer U, Bauer T, Hamm C, et al. Use and impact of intra-aortic balloon pump on mortality in patients with acute myocardial infarction complicated by cardiogenic shock: results of the Euro Heart Survey on PCI. Eurolntervention 2011; 7: 437-41.

19. Romeo F, Acconcia MC, Sergi D, et al. The outcome of intra-aortic balloon pump support in acute myocardial infarction complicated by cardiogenic shock according to the type of revascularization: a comprehensive meta-analysis. Am Heart J 2013; 165: 679-92.

20. Thiele H, Zeymer U, Neumann FJ, et al. Intraaortic balloon support for myocardial infarction with cardiogenic shock. N Engl J Med 2012; 367: 1287-96.

21. Thiele H, Zeymer U, Neumann FJ, et al. Intra-aortic balloon counterpulsation in acute myocardial infarction complicated by cardiogenic shock (IABP-SHOCK II): final 12 month results of a randomised, open-label trial. Lancet 2013; 382: 1638-45.

22. Dudek D, Siudak Z, Janzon M, et al. European registry on patients with ST-elevation myocardial infarction transferred for mechanical reperfusion with a special focus on early administration of abciximab - EUROTRANSFER Registry. Am Heart J 2008; 156: 1147-54. 
23. Rakowski T, Siudak Z, Dziewierz A, et al. Early abciximab administration before transfer for primary percutaneous coronary interventions for ST-elevation myocardial infarction reduces 1-year mortality in patients with high-risk profile. Results from EUROTRANSFER registry. Am Heart I 2009; 158: 569-75.

24. Siudak Z, Rakowski T, Dziewierz A, et al. Early abciximab use in ST-elevation myocardial infarction treated with primary percutaneous coronary intervention improves long-term outcome. Data from EUROTRANSFER Registry. Kardiol Pol 2010; 68: 539-43.

25. Jeger RV, Harkness SM, Ramanathan K, et al. Emergency revascularization in patients with cardiogenic shock on admission: a report from the SHOCK trial and registry. Eur Heart I 2006; 27: 664-70.

26. Dudek D, Legutko J, Siudak Z, et al. 26. Interventional cardiology in Poland in the year 2012. Summary report of the Association of Cardiovascular Interventions of the Polish Cardiac Society [Polish]. Kardiol Pol 2013; 71: 1213-9.

27. Singh M, White J, Hasdai D, et al. Long-term outcome and its predictors among patients with ST-segment elevation myocardial infarction complicated by shock: insights from the GUSTO-I trial. J Am Coll Cardiol 2007; 50: 1752-8.

28. Dudek D, Dziewierz A, Kleczynski P, et al. Long-term follow-up of mesh-covered stent implantation in patients with ST-segment elevation myocardial infarction. Kardiol Pol 2014; 72: 140-5.

29. Kübler P, Jankowska EA, Ferenc $M$, et al. Comparison of drug-eluting stents to bare-metal stents in ST-elevation myocardial infarction in long-term follow-up. Kardiol Pol 2013; 71: 25-31.

30. Abdel-Wahab M, Saad M, Kynast J, et al. Comparison of hospital mortality with intra-aortic balloon counterpulsation insertion before versus after primary percutaneous coronary intervention for cardiogenic shock complicating acute myocardial infarction. Am J Cardiol 2010; 105: 967-71.

31. Cheng JM, van Leeuwen MA, de Boer SP, et al. Impact of intra-aortic balloon pump support initiated before versus after primary percutaneous coronary intervention in patients with cardiogenic shock from acute myocardial infarction. Int J Cardiol 2013; 168: 3758-63. 